В статье представлены результаты изучения психологических преград и ограничений, препятствуюших развитию профессионализма психологов служебной деятельности ФСИН (Федеральной службы исполнения наказаний РФ). Проанализировано содержание понятий «психологические преграды» и «психологические ограничения», которые встречаются в служебной деятельности сотрудников психологических служб ФСИН России. Раскрыто их содержание на уровне общенаучного, психологического представления. Представлены результаты эмпирических исследований методом экспертного оценивания. Выявлены причины объективного, субъективного и объективносубъективного характера, раскрыто их психологическое содержание. Показана роль психологической диагностики в определении психологических преград и ограничений, уровня их выраженности. Показано, что роль преград и ограничений субъективного характера недооценивается психологами служебной деятельности ФСИН, поэтому целенаправленная работа по их компенсаџии проводится ограниченно. Для преодоления психологических преград и ограничений приоритетно предложено использовать саморазвитие и самоподготовку.

Ключевые слова: Федеральная служба исполнения наказаний, психолог, служебная деятельность, профессионализм, психологические преграды и ограничения, психологические условия и факторы.

Информация об авторах: Борисова Елена Владимировна, ORCID https://orcid.org/0000-0003-1476-7301, доктор педагогических наук, профессор, Военная академия РВСН имени Петра Великого, Россия.

E-mail: elenborisov@mail.ru

Кечил Дмитрий Иванович, ORCID https://orcid.org/0000-0001-7262-4638, кандидат психологических наук, Академия права и управления ФСИН России, подполковник внутренней службы, г. Рязань, Россия.

E-mail: dkechil@mail.ru

Дата поступления статьи: 29.07.2020.

Для цитирования: Борисова Е.В., Кечил Д.Н. Психологические преграды и ограничения, препятствующие развитию профессионализма психологов служебной деятельности (на примере психологов служебной деятельности ФСИН) // Вестник Костромского государственного университета. Серия: Педагогика. Психология. Социокинетика. 2020. T. 26, № 3. C. 93-97. DOI https://doi.org/10.34216/2073-1426-2020-26-3-93-97.

Yelena V. Borisova

The Military Academy of Strategic Rocket Troops after Peter the Great

Dmitriy I. Kechil

Academy of the FPS of Russia

\title{
PSYCHOLOGICAL BARRIERS AND RESTRICTIONS \\ THAT PREVENT PROFESSIONAL PSYCHOLOGISTS' DEVELOPMENT IN THEIR WORK (in terms of service psychologists of the FPS of Russia)
}

The article presents the results of research on psychological barriers and restrictions that prevent professional psychologists' development during their work at the Federal Penitentiary Service of Russia. The content of the concepts "psychological barriers» and "psychological restrictions» is analysed. The content is disclosed at the general level. The article describes the results of empirical research of psychological barriers and limitations among psychologists of the FPS of Russia, the main method of which included expert evaluation. The causes of objective, subjective and objectivesubjective nature were identified, and their psychological content was revealed. The role of psychological diagnostics in determining psychological barriers and restrictions, their level of expression is shown. It is noted that the role of barriers and restrictions of a subjective nature is underestimated by psychologists of the service activity of the Federal penitentiary service, thus purposeful work on their compensation is limited. In order to overcome psychological barriers and constraints, use of different methods and technologies, priority is given to self-development.

Keywords: Federal Penitentiary Service, service psychologist, professionalism, psychological barriers and restrictions, psychological conditions and factors.

Information about the authors: Yelena V. Borisova, ORCID https://orcid.org/0000-0003-1476-7301, Doctor of Pedagogic Sciences, certified professor, Leading Researcher, The Military Academy of Strategic Rocket Troops after Peter the Great, Russia.

E-mail: elenborisov@mail.ru 
Dmitriy I. Kechil, ORCID https://orcid.org/0000-0001-7262-4638, Candidate of Psychological Sciences, senior lecturer at the department of social psychology and social work, Academy of the FPS of Russia, Ryazan, Russia.

E-mail: dkechil@mail.ru

Article received: July 29, 2020.

For citation: Borisova Ye.V., Kechil D.I. Psychological barriers and restrictions that prevent professional psychologists' development in their work (in terms of service psychologists of the FPS of Russia). Vestnik of Kostroma State University. Series: Pedagogy. Psychology. Sociokinetics, 2020, vol. 26, № 3, pp. $93-97$ (In Russ.). DOI https://doi.org/10.34216/20731426-2020-26-3-93-97.

$\Pi$ ри разработке проблемы профессионализма в психологическом аспекте повышенное внимание уделяется определению путей, условий и факторов, которые способствуют его развитию. В то же время не менее важной задачей является определение психологических детерминантов (субъективных и объективных причин, условий, факторов и пр.), которые мешают или препятствует развитию профессионализма. Данные детерминанты могут быть как объективными (низкий неявный запрос на профессионализм), так и субъективными (недостаточно развитые личностные и профессиональные свойства личности, негативные внутренние условия). Исследователи психологии труда (Бодров В.А., Геллерштейн С.Г., Голубев Г.Г., Зеер Ф.Э., Климов Е.А., Платонов К.К., Стрелков Ю.К., Толочек В.А. и др.) отмечают, что таковыми являются психологические препятствия и ограничения.

В последнее время данные детерминанты стали объектами углубленных психологических исследований. Рядом ученых проведены исследования преград и ограничений: препятствующих или сдерживающих развитие профессионализма государственных служащих (Деркач А.А., Марков В.Н., Синягин Ю.В. и др.); препятствующих развитию конкурентоспособности предпринимателей [Посохова: 160]; ограничивающих самореализацию в художественно-творческой деятельности (Борисов М.Б., Галкина Ю.И., Соболева О.С., Фетисова Е.В. и др.).

В работах В.Г. Зазыкина и др. введены основные понятия, связанные с исследуемой проблемой:

- «психологические ограничения - психологические причины, условия и факторы, не дающие возможности продуктивно развиваться личностнопрофессиональному свойству субъекта деятельности, ограничиваются пределами определенного диапазона;

- психологические препятствия - психологические причины, задерживающие продуктивное развитие какого-либо свойства субъекта;

- психологические условия - это значимые обстоятельства, имеющие субъективный характер, от которых что-то зависит;

- психологические факторы - значимые психологические причины, имеющие субъективный характер, от которых что-то зависит» [Дьячкова, Зазыкин, Смирнова: 18].

А.К. Марков отмечает, что «важнейшей характерной чертой препятствий и ограничений является их субъективный характер, то есть отражаются в психологических особенностях самого субъекта» [Марков: 212]. Одновременно субъективизм в причинах психологических препятствий и ограничений субъектом часто не осознается, что ограничивает возможности в их компенсации. Также считается, что общими психологическими преградами и ограничениями, мешающими развитию профессионализма независимо от сферы профессиональной деятельности, являются качества или свойства субъекта деятельности, которые по своему уровню развития и содержанию являются противоположными качествам и свойствам, имеющимся у профессионалов (Градов С.С., Карпенко А.С. и др.). В то же время большее распространение получил подход, основанный на непосредственном психологическом изучении преград и ограничений.

Проведенный анализ результатов исследований, направленных на изучение психологических преград и ограничений, препятствующих продуктивному личностно-профессиональному развитию и снижающих эффективность деятельности, позволил выявить наиболее значимые. К ним отнесены: недостаточный уровень развития интеллектуальных и волевых качеств; низкая активность; сильные, плохо контролируемые акцентуации; неосознаваемый внутриличностный конфликт; экстернальный локус контроля; высокий уровень напряженности и тревожности; выраженное стремление к избеганию неудач; неадекватность самооценки; низкий уровень саморегуляции, психической устойчивости и самоконтроля; отрицательные психологические установки на собственные потенциальные возможности; нежелание осуществлять саморазвитие. Практика профессиональной деятельности свидетельствует, что ряд из отмеченных препятствий и ограничений присущи психологам служебной деятельности ФСИН.

В работе А.В. Посоховой определяется, что «психологические преграды и ограничения, мешающие развитию многих личностно-профессиональных свойств субъектов деятельности, можно описать в виде системы, которая имеет структуру функционально-динамической системы личности» [Посохова: 162].

Система психологических препятствий и ограничений включает в себя ряд подструктур:

- «биологически обусловленную, проявляющуюся в низком уровне личностного потенциала, отсутствии силы личности и деятельности, отсутствии творческой активности; 
- психических свойств, характеризующихся: недостаточно развитыми функциями когнитивных процессов (внимания, памяти, мышления); отсутствием системности мышления, глубины ума и его практической направленности; отсутствием интуиции; низкой способностью строить прогнозы и предположения;

- характера, отражающую: наличие сильных и плохо контролируемых акцентуаций, низкое психическое сопротивление; слабые волевые проявления; безынициативность; неопределенность; безответственность.

- профессиональную, обнаруживающую: низкий уровень профессиональных навыков; слаборазвитую систему профессиональных владений; отсутствие склонности к профессиональному творчеству; непродуктивное отражение собственной и чужой деятельности; неспособность влиять на других, объединять их; низкую личностную эффективность.

- ориентации, состоящую из: низкой инновационной активности; непродуктивной самооценки; отсутствия направленности профессиональных достижений; слабой системы мотивации и чувств; низкой морально-нравственная нормальности деятельности, поведения и отношений; отсутствия значимых личностных и профессиональных норм» [Посохова:164].

Исследования по развитию профессионализма психологов, ориентированных на психологические преграды и ограничения, используют распределение по уровню их проявлений. Выявлены три уровня: незначительные, существенные и значительные психологические препятствия и ограничения. Также существует классификация психологических препятствий и ограничений, которые анализируются в сочетании с уровнем развития личностнопрофессиональных качеств.

Важным вопросом в исследуемой проблематике является выбор инструментальной и неинструментальной психологической диагностики. Или диагностику проводят по косвенным признакам, например: что мешает раскрытию и преумножению личностного потенциала? блокирует возвышение профессиональных стандартов? способствует формированию неадекватного образа «Я-профессионал»? и др.

Проведенный теоретический анализ проблемы позволил выявить необходимые предпосылки для эмпирического исследования психологических препятствий и ограничений, мешающих развитию профессионализма психологов служебной деятельности ФСИН.

Ввиду того, что объект отличается высоким уровнем психологической сложности, методом исследования определено экспертное оценивание.

Экспертами выбраны руководители и ведущие специалисты психологических лабораторий тер- риториальных органов ФСИН РФ. Всего, согласно требованиям, предъявляемым к данному методу, в исследовании участвовало 50 экспертов, из них 25 \% мужчин и 75 \% женщин. По стажу работы экспертов выделены доли: пятая часть от одного года до трех лет: половина - свыше 5 до 10 лет, от 10 до 15 лет - четвертая часть и более 20 лет $-5 \%$. Таким образом, можно утверждать, что в экспертном оценивании приняли участие опытные специалисты.

Результатами опросов экспертов явилось подтверждение актуальности исследуемой проблемы. Подавляющее большинство опрощенных - 80 \% («да» $-35 \%$ и «скорее да» $-45 \%$ отметили, что действительно существуют психологические преграды и ограничения, которые негативно сказываются на эффективности деятельности, продуктивности личностно-профессионального развития и движения к профессионализму психологов служебной деятельности ФСИН.

$55 \%$ экспертов полагают, что в этих препятствиях и ограничениях объективное и субъективное проявляется примерно в равных пропорциях. Около 30 \% считают, что более значимыми являются препятствия и ограничения объективного характера. Полностью субъективными их не назвал ни один эксперт. Вообще говоря, отразилась взвешенная оценка ситуации, хотя и проявилась известная в психологии труда недооценка значимости субъективных факторов.

В дальнейшей работе эксперты из представленного перечня основных препятствий и ограничений, мешающих повышению эффективности деятельности, продуктивности личностно-профессионального развития и движению к профессионализму психологов служебной деятельности ФСИН, выбрали наиболее значимые (выбор был не менее семи из представленных, общая сумма более $100 \%)$ :

- недостаточное стимулирование труда психологов (70 \% упоминаний или выборов);

- негативные особенности среды профессиональных взаимодействий (60 \%);

- узость карьерной перспективы (40 \%);

- отсутствие направленности на профессиональные достижения (45\%);

- профессиональная деформация (35\%);

- невысокая активность (25\%);

- недостаток упорства, целеустремленности, настойчивости (20\%);

- отсутствие ориентирующих личностных и профессиональных стандартов (20\%);

- неадекватная профессиональным задачам мотивационно-смысловая система (15\%);

- недостаточный потенциал (15\%).

Значимость остальных причин и факторов проявилась в менее 10 \% выборов (упоминаний). По результатам работы экспертов к перечню были добавлены: низкая психическая устойчивость к стрессам, 
недостаточная сила личности, низкая самоэффективность, лень, индифферентное отношение.

Следует отметить, что 70 \% экспертов считают, что у них как специалистов присутствуют некоторые из основных препятствий и ограничений, мешающих повышению эффективности деятельности, продуктивности личностно-профессионального развития и движению к профессионализму психологов служебной деятельности ФСИН. $30 \%$ экспертов отметили один-два субъективных фактора, в частности недостаток волевых качеств, низкие профессиональные стандарты. При этом никто из экспертов не упомянул о наличии у них профессиональной деформации.

Практикующие психологи служебной деятельности ФСИН в первую очередь отмечали объективные факторы, препятствующие развитию их профессионализма, которые в основном имеют организационный характер, то есть являются потенциально устранимыми.

Отмечены и значимые субъективные факторы. Важно отметить, что некоторые из них корректировать трудно, а некоторые возможно, причем в широком диапазоне. В частности, активность и потенциал являются биологически обусловленным свойством личности, их развитие в принципе возможно, но в узком диапазоне (Кричевский Р.Л., Маркова А.К., Толочек В.А.). Следовательно, для компенсации данной преграды или ограничения необходима организация психологического профессионального отбора для психологов служебной деятельности ФСИН. Упорство, целеустремленность, настойчивость относятся к волевым качествам личности (Иванников В.А., Селиванов В.И. и др.). При должной мотивации их можно успешно развивать. Недостаточная направленность на профессиональные достижения, низкие ориентирующие личностные и профессиональные стандарты, неадекватная профессиональным задачам мотивационно-смысловая система относятся к подструктуре направленности личности, компоненты которой обладают свойством развиваться. Объективно необходим более конкретный и обоснованный запрос на профессионализм психологов служебной деятельности со стороны системы ФСИН, что положительно скажется на повышении стандартов и эталонов. Компенсировать профессиональную деформацию как психологическую преграду и ограничение в развитии профессионализма психологов служебной деятельности ФСИН, по свидетельству практиков, довольно сложно, хотя и в этом направлении имеются позитивные результаты.

Заметим, что в проводимом исследовании установлено определенное сходство между психологическими преградами и ограничениями, препятствующими развитию конкурентоспособности предпринимателей, и теми, что отмечены у психологов служебной деятельности ФСИН. В первую очередь к ним относятся «недостаток воли и волевых качеств, особенно решительности, упорства, настойчивости; низкий уровень активности; недостаток силы личности; психическая неустойчивость, особенно к экстремальным и стресс-факторам» [Посохова: 162]. Это свидетельствует о регуляторных механизмах препятствий и ограничений.

Итогом выполненного теоретического анализа и экспертной работы стало ранжирование по степени значимости отмеченных причин, условий и факторов, что является уточнением и конкретизацией полученных ранее результатов. Установлено: $80 \%$ отмеченных факторов имеют субъективную и объективно-субъективную причинную обусловленность, то есть, вообще говоря, их можно устранить, к ним относятся:

- негативные особенности среды профессиональных взаимодействий;

- недостаточный потенциал;

- недостаточные прогностические возможности;

- недостаточное стимулирование труда психолога служебной деятельности;

- невысокая активность;

- профессиональная деформация;

- отсутствие направленности на личностнопрофессиональное развитие;

- низкие личностные и профессиональные стандарты;

- узость карьерной перспективы;

- недостаток силы личности, слабая воля;

- недостаточная интуиция;

- низкая нравственная нормативность поведения и деятельности;

- негативная мотивационно-смысловая сфера.

Таким образом, развитие профессионализма психологов служебной деятельности ФСИН возможно, в частности, и за счет психологических ресурсов личности. По мнению экспертов, психологические ограничения и препятствия можно устранить или компенсировать - 65 \% положительных ответов (25\% «да» и $40 \%$ «скорее да, чем нет»); возможно, но в узком диапазоне - $25 \%$ экспертов. И всего 5 \% полагают - нельзя полностью устранить или компенсировать.

Наиболее конструктивными путями компенсации или устранения психологических преград и ограничений, препятствующих развитию профессионализма психологов служебной деятельности ФСИН, по мнению экспертов, являются: саморазвитие (55\%); анализ и освоение передового опыта других психологов служебной деятельности ФСИН (45 \%); специальные психологические тренинги развития личностно-профессиональных качеств (35\%); следует использовать любые имеющиеся возможности (10\%).

Приоритет, отданный саморазвитию, имеет свои причины. Саморазвитие - это личностный рост путем самостоятельных занятий и упражнений. Са- 
моразвитие может быть непрерывным процессом в профессиональной деятельности, что важно для развития профессионализма. В то же время саморазвитие, как и самообучение, имеет определенные сложности в реализации: отсутствие методического руководства, нечеткость обратных связей, недостаточную систематичность. Продуктивность саморазвития обусловливается постановкой четких и ясных целей; определением этапов ее достижения; определением временного ресурса; определение средств, возможностей для саморазвития. Успешность саморазвития психологов служебной деятельности ФСИН во многом определяется имеющимися информационными и технологическими ресурсами. Психологи служебной деятельности ФСИН, как показало экспертное оценивание, для компенсации психологических преград и ограничений, помимо саморазвития, широко используют самоподготовку, обучение и тренинги.

Основным результатом проведенного исследования является обоснование необходимости преодоления или компенсации психологических преград и ограничений, препятствующих развитию профессионализма психологов служебной деятельности ФСИН на основе анализа действующих психологических механизмов. Определено, что выбор методов и технологий компенсации или преодоления должен базировать на точном определении вида психологических преград и ограничений, их уровня или силы проявления. Также нашло подтверждение о необходимости определять связи с конкретным личностнопрофессиональным свойством, обусловливающим уровень персональной конкурентоспособности, диапазон изменений, возможности компенсации за счет приоритетного развития других личностнопрофессиональных свойств, находящихся в системных связях [Обозов: 152].

\section{Список литературы}

Дьячкова Е.В., Зазыкин В.Г., Смирнов Е.А. Психолого-акмеологические основы успешной карье- ры. Иваново: ИФ РАНХ и ГС и изд. дом «Иваново», 2012. 224 c.

Марков В.Н. Личностно-профессиональный потенциал управленца и его оценка. М.: РАГС, 2001. 262 c.

Обозов Н.Н. Интенсивная подготовка менеджера. СПб.: БХВ: Петербург, 2011. 240 с.

Посохова A.B. Психологические преграды и ограничения при формировании конкурентоспособности предпринимателей // Мир образования образование в мире. 2016. № 1 (61). С. 160-165.

Профессионализм деятельности: теоретические основы и актуальные проблемы / под ред. В.И. Жукова и др. М.: РГСУ, 2005. Т. 2. 517 с.

\section{References}

D'iachkova E.V., Zazykin V.G., Smirnov E.A. Psikhologo-akmeologicheskie osnovy uspeshnoi kar'ery [Psychological and acmeological fundamentals of a successful career]. The Ivanovo branch of the RANEPA and publishing house "Ivanovo"], 2012, 224 p. (In Russ.)

Markov V.N. Lichnostno-professional'nyi potentsial upravlentsa $i$ ego otsenka [Personal and professional potential of a manager and its assessment]. Moscow, RAGS Publ., 2001, 262 p. (In Russ.)

Obozov N.N. Intensivnaia podgotovka menedzhera [Intensive training of managers]. Saint-Petersburg, BKhV, Peterburg Publ., 2011, 240 p. (In Russ.)

Posokhova A.V. Psikhologicheskie pregrady $i$ ogranicheniia pri formirovanii konkurentosposobnosti predprinimatelei [Psychological barriers and restrictions in forming the competitiveness of entrepreneurs]. Mir obrazovaniia - obrazovanie $v$ mire [World of education - education in the world], 2016, № 1 (61), pp. 160-165. (In Russ.)

Professionalizm deiatel'nosti: teoreticheskie osnovy $i$ aktual'nye problem [Professionalism of activity: theoretical bases and actual problems.], ed. by V.I. Zhukov. Moscow, RGSU Publ., 2005, vol. 2, 517 p. (In Russ.) 